\title{
Erratum to: Human Health and Physical Activity During Heat Exposure
}

\author{
Yuri Hosokawa
}

\section{Erratum to: Y. Hosokawa (ed.), Human Health \\ and Physical Activity During Heat Exposure, https://doi.org/10.1007/978-3-319-75889-3}

The original version of the book had a typographical error that resulted in 'Heath' appearing instead of 'Health' and these changes have been updated in the Front matter and in the Title of Chapter 3 and Affiliation Detail in Chapter 4.
A. L. Williams
Occupational Health Clinic, Directorate of Public Health,
Walter Reed National Military Medical Center, Bethesda, MD, USA

\footnotetext{
The updated online versions of these chapters can be found at https://doi.org/10.1007/978-3-319-75889-3_3 https://doi.org/10.1007/978-3-319-75889-3_4 https://doi.org/10.1007/978-3-319-75889-3
}

(C) The Author(s), under exclusive licence to Springer International Publishing AG, 